\title{
CLINICAL WASTE MANAGEMENT PRACTICES IN DISTRICT FAISALABAD
}

Syed Shahzaib Ali ${ }^{1}$, Nimrah Ijaz ${ }^{1}$, Nafeesa Aman ${ }^{1}$, Abdul Nasir ${ }^{1}$, Lubna Anjum ${ }^{2}$ and Ijaz Ahmad Randhawa ${ }^{3}$

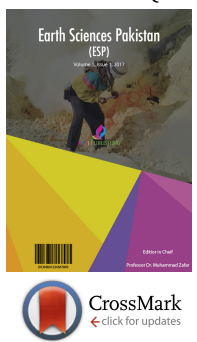

\author{
${ }^{1}$ Department of Structures \& Environmental Engineering, University of Agriculture, Faisalabad, Pakistan. \\ ${ }^{2}$ Department of Irrigation \&Drainage, University of Agriculture, Faisalabad, Pakistan. \\ ${ }^{3}$ Head of the Department, Civil Engineering, The University of Faisalabad, Faisalabad.
}

This is an open access article distributed under the Creative Commons Attribution License, which permits unrestricted use, distribution, and reproduction in any medium, provided the original work is properly cited

\section{ARTICLE DETAILS}

\section{ABSTRACT}

\section{Article history:}

Received 25 August 2017 Accepted 20 October 2017 Available online 7 November 2017

Keywords:

hospital, waste, analysis

\begin{abstract}
Hospital waste is categorized as a very dangerous waste type as it possesses many pathogenic elements and it can cause harmful human health effects. This research shows the survey and field investigation conducted at government hospitals located in Faisalabad. The quantitative waste analysis showed that 55\% non-infectious, 15\% infectious, 25\% bio-hazardous, $2 \%$ sharps and $3 \%$ chemical waste is generation in these hospitals. Few main hospitals have their own incinerator but still either they are not working efficiency or insufficient to handle waste. However, this paper deals with the design of incinerator for small scale hospitals. The proposed incinerator has three chambers: primary chamber (temperature range 500-7000c), secondary chamber (temperature range 700-900oc), and tertiary chamber (temperature range 900-12000c). Situation analysis confirmed the earlier view that a hospital waste management project should be implemented at this hospital and an intensive training programmed, at all levels, and is required to deal effectively with this problem.
\end{abstract}

\section{INTRODUCTION}

The hospital and community are equally responsible for the management of hospital waste. Hospital waste can be alarming to the environment as well as community. It needs proper handling and treatment superior to its final disposal. Increase in the number of hospitals ultimately increases quantity of waste which is dumped without any treatment. According to author that people who are dealing with hospital waste are unknown to infectious waste proper definition due to which there is increase in waste generation rate and disposal cost [1]. So as a result, there is a need to educate people about these wastes and proper training should be given to them. In Pakistan, a patient generates 1.5-2 kg of waste per bed/day [2]. The waste includes both the non-infectious and infectious waste. Proper segregation and disposable of hospital waste is required at the grass-root level [3]. Another author analysis the hospital waste by comparison approach by dividing hospitals into groups for easy evaluation performance [2]. Mostly works in hospital don't know about hospital waste management plan and techniques, so there is a need to train them. This is also said in a study by some researchers who concluded that generally workers of private hospitals know little more knowledge about hospital waste management than public hospital workers but overall material availability on waste handling especially waste segregation at source point is low and not up to mark [4].

Table 1: Type of waste and container used for disposing of wastes

\begin{tabular}{|l|l|l|l|}
\hline Waste Type & Infectious waste & Non-infectious waste & Bio Hazards \\
\hline waste includes & $\begin{array}{l}\text { Body parts } \\
\text { Blood and body fluids } \\
\text { Waste from infectious }\end{array}$ & $\begin{array}{l}\text { Paper and cardboard } \\
\text { Packaging } \\
\text { Food waste }\end{array}$ & $\begin{array}{l}\text { Empty drips } \\
\text { Syringes } \\
\text { Needles }\end{array}$ \\
\hline & $\begin{array}{l}\text { patients } \\
\text { Waste from surgery. } \\
\text { Culture from laboratory }\end{array}$ & $\begin{array}{l}\text { Saw and knifes } \\
\text { Used pharmaceutical } \\
\text { products }\end{array}$ \\
\hline Type of receptacle & $\begin{array}{l}\text { Container lined } \\
\text { With plastic bag }\end{array}$ & $\begin{array}{l}\text { Container lined } \\
\text { With plastic bag }\end{array}$ & $\begin{array}{l}\text { Safety box or } \\
\text { sealable box }\end{array}$ \\
\hline Color & Yellow & Green & Red \\
\hline Characteristics & Strong and leak proof & $\begin{array}{l}\text { Strong and tear } \\
\text { resistant }\end{array}$ & $\begin{array}{l}\text { Penetration and } \\
\text { leak resistant }\end{array}$ \\
\hline Destination & $\begin{array}{l}\text { Incineration and secured } \\
\text { landfill }\end{array}$ & Landfill & $\begin{array}{l}\text { Incineration nd } \\
\text { secured landfill }\end{array}$ \\
\hline
\end{tabular}

Hospitals waste one of the most diverse and difficult to manage waste streams of any institution. Hospital waste includes hazardous chemical, infectious, and radioactive wastes, along with solid waste-and they generate it in close proximity to people, both workers and patients whose well-being and safety must be safeguarded [5]. Hospitals are not factories where a hazardous process or material can always be easily isolated. Hospitals work with and serve people. Hospitals provide services throughout their facilities to patients and families. Hospital waste have rapidly increased in past years due to the increase in population, number and size of bio-medical facilities, as well as the use of disposal product. This waste adversely affects the environment by contaminating air, soil, and water. The risk of in efficiency and infection resulting from poor management of hospital waste is very high in which syringes are not properly disposed of which result in spread of disease such as hepatitis, HIV, And AIDS. These diseases due to improper disposal of infectious hospital substance and this is great concern for health practitioners and policy makers.

The major purpose of this study is to assess the clinical waste management practices in district Faisalabad. To achieve this goal the following specific objectives were to analyze the present practices of hospital waste management system and Suggestion for the improvement of the existing system. Design the incinerator plant for hospital waste management. Solid waste generated from the hospital called hospital solid waste. Sewerage is not included in hospital waste.

\section{METHODOLOGY}

Methodology means to explain various tools and technique for the collection and analysis of data related to the study under investigation. The study was conducted different big hospitals in Faisalabad [6]. Hospitals were surveyed conveniently covering three categories e.g. government trust and private. Methodology was consisting on two phases first phase was data collection and second phase was analysis. In first phase was consisting on initial survey of different hospitals and study related on-site inspection, waste collection area, waste collection existing system, waste disposal site, disposal site related impact and its management. Different hospitals were visited at initial stage to select a small and large scale of hospitals keeping in view their waste management systems. The study was carried out from January - April 2017. Six parameters waste generation, segregation, handling, transporting, and final disposal were observed in this study. Primary data was collected by the interview of hospitals authorities and after collecting data comparing with WHO standards [7]. Personal observation of workers of waste management team was it applies all international standards in hospitals. Second phase was based on sampling and analysis of waste. Different departments of hospitals including emergency, O.P.D, operation theater, surgical ward, gynecology ward, general ward, X-ray laboratory, pathology laboratory, labor room , staff room, admin block were visited and observed for data collection. In order to determine waste characterization, it comprises infectious, noninfectious, bio-hazard waste and chemical waste. In hospitals all type of waste collected separately color coated baskets were used in premises. Yellow basket for infectious waste, red for bio-hazard and green or black was used for non-infectious waste. Personal visits of hospitals regularly and waste management staff and sanitary worker indivisibly interviewed 


\section{RESULTS AND DISCUSSION}

The study showed that the hospitals are maintaining satisfactory cleanliness and hygienic conditions within the building boundary. Overall environment of hospitals is healthy and acceptable. There is highly maintained sterilization system and cleanliness standard in operation theaters. Polythene bags are used for waste collection and disposal. In spite of all the care taken by staff during process there are some drawbacks to meet international standard. Various improvements can be made still to refine the process [8]. Proper protection measures are not followed by staff during transportation of waste. On the other hand, hospitals don't retain their own incinerator or other alternative treatment method. Instead they transport their waste to a faraway place to incinerate twice a week. However, no proper system to inspect or verify that waste is disposed properly or not. Also no appropriate confirmation of medical checkup of sanitary staff on regular basis those have direct involvement with waste handling in hospital. In hospitals mostly observed percentage of infectious, noninfectious, bio hazard, sharp or chemical waste is observed.

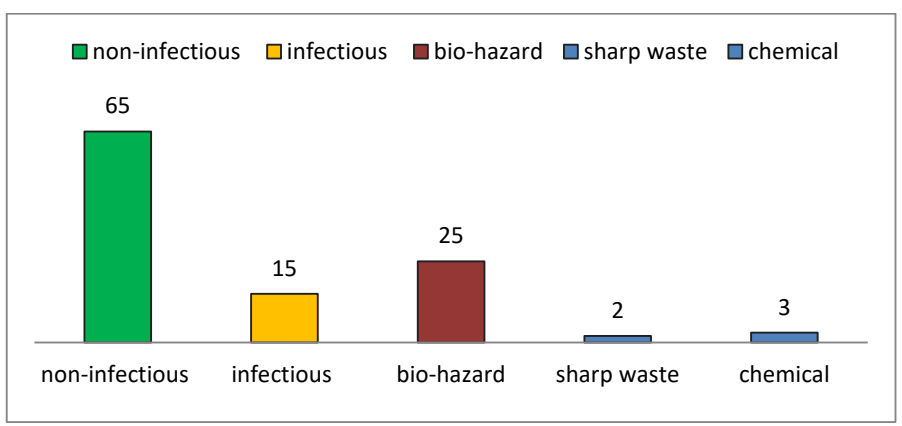

Figure 1: Percentage of different hospital waste types

The Figure 2 shows waste composition in large hospital and small hospital in district Faisalabad. Large hospital daily waste generation rate is $1200 \mathrm{~kg}$ in which non-infectious waste contribution $660 \mathrm{~kg}$, infectious waste $180 \mathrm{~kg}$, bio-hazard $300 \mathrm{~kg}$, sharp $24 \mathrm{~kg}$ and chemical $36 \mathrm{~kg}$. In small hospital, daily waste generation rate is $150 \mathrm{~kg}$ in which non-infectious waste contribution $82.5 \mathrm{~kg}$, infectious waste $22.5 \mathrm{~kg}$, bio-hazard $37.5 \mathrm{~kg}$, sharp $3 \mathrm{~kg}$, and chemical $4.5 \mathrm{~kg}$. Keeping in view the above said waste composition the next step was to design incinerator for a small-scale waste management.

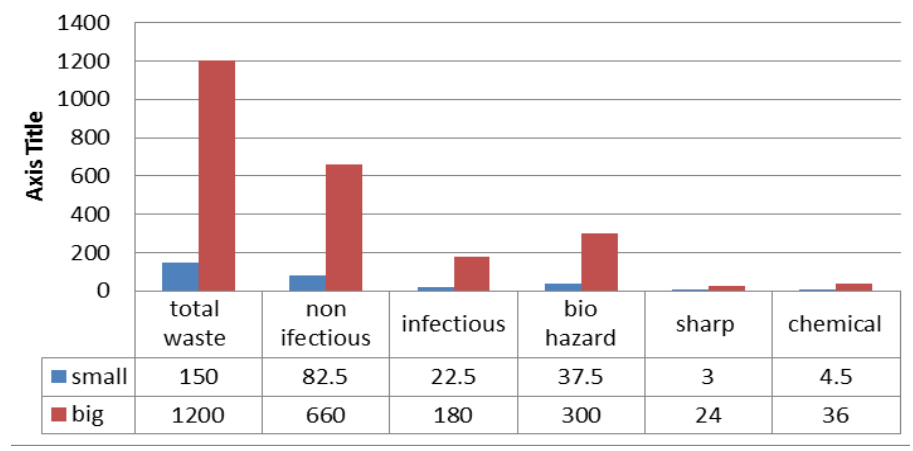

Figure 2: Comparison of generated waste in hospital

\section{INCINERATION}

Incineration is a disposal technique of hospital waste. It's a complete combustion process in which completely burns all toxic waste of hospital. General incinerator shell is specifically designed to destroy all type of medical waste [9]. The incinerator capacity may vary according to the type and quantity waste generated in hospital per day. Some technical detail of incinerator is waste feeding system, charging door, and primary combustion chamber, secondary \& tertiary combustion chamber. Waste feeding door of incinerator is carried out manually. Charging door shall be enough to allow the normal plastic bag (fully with waste) to be charge in to be charge in to the incinerator without any obstruction. Primary combustion chamber design to allow batch loading. In this chamber temperature ranges $500-700 \mathrm{oc}$. all waste is burnt in this chamber and convert into ash. At least one thermocouple is installing on the top of primary chamber. Thermocouple is strategically positioned so as to measure temperature inside the furnace accurately [10]. At least one unit of ash door is provided for this chamber and at least one blower installed in this chamber. Secondary combustion chamber is equipped with a secondary combustion chamber to ensure complete destruction of any incomplete combustion of burnt flue gases. This chamber has temperature range between $700-900 \mathrm{oc}$. At least one unit of temperature control and indicator system is installed in this chamber. Tertiary chamber has temperature range of $900-1200$ oc. A temperature controller device should install having range $0-1600 \mathrm{oc}$.

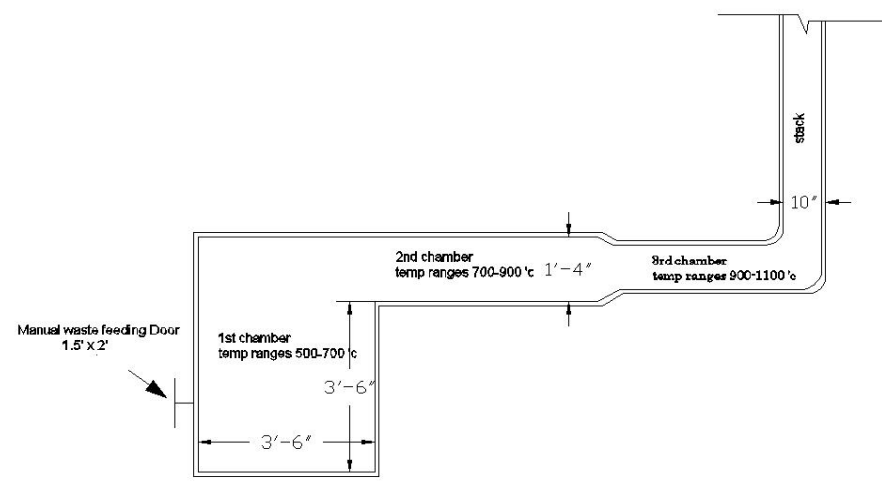

Figure 3: Structure of incinerator

\section{CONCLUSION}

In this research, current practices of hospital waste management are observed to determine that how much appropriate technologies are in use for waste management in hospitals. From the results obtained by research study shows that segregation of different healthcare waste is performed properly as they are following the Hospital Waste Management rule 2005. Both primary and secondary segregations are done in an effective way. Also, staff of hospital has some knowledge about clinical waste management. But still there is a need for workshops and capacity building programs to be held for all employees concerned with hospital waste management. On site segregation of all type of hospital waste is done properly but need more training related to infection control involved in hospital waste management. Situation analysis confirmed the earlier view that a hospital waste management project should be implemented at this hospital and an intensive training programmed, at all levels, and is required to deal effectively with this problem.

\section{RECOMMENDATION}

Clinical directors, nurse manager and manager must support the strategy and ensure that all staff observes the rule:

1 Once a waste management plan is made and is implemented in a hospital, it should be sustainable one.

2 The questionnaires prepared for each category of hospital staff can be used as a tool for the quantitative assessment of the waste management.

3 Education about the use of personal protective equipment, waste handling and other processing must be given to workers as in Pakistan they are mostly less educated and have no idea about hazardous materials and their effects on health of society.

$4 \quad$ Regular monitoring and assessment by independent team of investigation must be done to ensure proper implementation of action plan.

5 For effective management of hospital waste, it is necessary to make a plan. But before making plan it is necessary to collect information about current situation of hospital waste management process.

\section{REFERENCES}

[1] Arshad, N., Nayyar, S., Amin, F., and Mahmood, K. T. 2011. Hospital waste disposal: A review article. Journal of Pharmaceutical Sciences and Research, 3 (8), 1412-1419.

[2] Sanwal, A., Mahmood, U., Malik, A.U., Aziz, F., Naghman, R., and Ahmed, I. Current Hospital Waste Management Practices in Pakistan: Case Study and Curative Measures. American Institute of Science, 1 (3), 125-129.

[3] International Committee of the Red Cross. 2011. Medical Waste Management, ICRC, November.

[4] Oli, Nnamdi, A., Ekejindu, C.C., Adje, D.U., Ezeobi, I., Ejiofor, O.S., Ibeh, C.C., and Ubajaka, C.F. 2016. Healthcare waste management in selected government and private hospitals in Southeast Nigeria. Asian Pacific Journal of Tropical Biomedicine, 6 (1), 84-89.

[5] Health and Safety Commission. 1999. Safe disposal of clinical waste, 2nd ed. Suffolk: HSE Books.

[6] Analysis of Priority Waste Streams. 1993. Healthcare Waste. Information Document, Commission of the European Communities December. 
[7] Environment Agency. 2002. Risk assessment for handling and disposal of clinical wastes. London, UK: Environment Agency, p. 1_119 [RD Report P4-073/TR].

[8] Thakur, Y., and Katocha, S. S. 2012. Emerging Technologies in Biomedical Waste Treatment and Disposal. Chemical Engineering, 29.
[9] Yasmeen, T., Islam, F., Amin, S., Ali, S., Abbas, F., Virk, R., and Majid, T. 2013. Manuscript Info Abstract. International Journal, 1 (10), 482-494.

[10] Yantao, X. 2015. Comparison of hospital medical waste generation rate based on diagnosis-related groups. Journal of Cleaner Production, 100 (2015), 202-207. 